\title{
LXIV. Case of femoral hernia, with some peculiarities, sucessfully treated by an operation
}

\author{
John Taunton
}

To cite this article: John Taunton (1812) LXIV. Case of femoral hernia, with some peculiarities, sucessfully treated by an operation, Philosophical Magazine Series 1, 40:175, 365-367, DOI: 10.1080/14786441208638249

To link to this article: http://dx.doi.org/10.1080/14786441208638249

里 Published online: 27 Jul 2009.

Submit your article to this journal $\sqsubset \pi$

Џll Article views: 2

Q View related articles $₫$ 
Platina appears to be characterized no less by in valuable properties than by its disposition to form peculiar triple compounds; and there can be little doubt but that aimore extensive acquaintance with the combinations of thës metal will add considerably to the number of such substances - It would be an interestinginquiry, whether the same laws which seem to govern the formation of binary compounds, extend likewise to thoseof ternary compounds. For an investigation of thiskind no metal seems so well adapted as platina; whether we consider the variety of its compounds, of the simplicity of the results furnished by their decomposition.

Some of the preceding combinations seem to agree with the doctrine of definite proportions, and to correspond very nearly with experiments made by Professor. Berzelius of Stockholm. But there is not the same coincidence with others. Whilst I cannot but regret the imperfection of this investigation, I indulge a hope, that should the subject hereafter be thought worthy of a more rigorous inquiry, I shat be able by a careful attention to render it more complete.

LXIV. Case of Femoral.Herinia, with some Peculiarities, sucessfully treated by an Operation. By Joun Taunton, Surgeon to the City of London Truss Society, the City and Finslury Dispensaries, and Lecturer on Anatomy and Surgery.

$M_{\text {Rs. M. aged 30, a patieent in the City of London Truss }}$ Snciety, recommended by Mr. Lincoln; Hatton Garden, has had femoral hernia on the right side for about six months; but this gave very little uneasiness, as the tumour was very small, and could at all times be returned by slight pressure.

July 16, 1812, it became painful and irreducible; the pain was referred to the umbilicus, and was preceded by hiccough, sickness', and vomiting. On the 17 th she had a stool, but the symptoms continued; the hiccough, sickmess, and vomiting were worse.

On the 19 th, 3 A.M. I visited her for the first time, found the tumour small, but tense and irreducible. The pain, on attempting to reduce it, was referred to the umbilicus and region of the stomach. Two of the following pills were directed to be taken every second hour :

R. Hydrargyri submuriatis $\mathbf{g r} . \mathbf{x}$.

Extracti colocyntbidis 3 i.

Opii gr.iii.

Olei menth piperitz gtt, vii. Misce.

Fiant pilulæ viginti. 
9 P.M. The pills remained on the storsacb; the hiccongh and sickness were less. An enema was directed to be given.

20. 5 A.M. Much the same as on the preceding evening. Another box of pills was ordered to be taken as before; the same as the former, excepting the omission of the opium. The tobacco enema was directed to be given, which had the effect of producing a stool, after which she seemed a little reiteved, but the hernia remained in the same state.

4 P. M. Restless, skin dry, tongue furred, the hiccough and sickness worse.

9 P. M. The unfavourable symptoms had all increased considerably. On proposing the operation it was agreed to immediately, and performed soon after 10 P. M. The peritoneal sac was very thin, and contained only a few drops of serum; the contents of the sac was an adipose tumour ** having exactly the appearance of condensed omentum. This tumour grew from the coat of the intestine, by a small neck. No part of the canal of the intestine was included in the stricture.

The stricture was dilated in the usual way inwards and downwards towards the symphysis pubis. Immediately on the part being returned she experienced relief, and said she felt much more comfortable. The wound was dressed with lint and adhesive plaster, secured by a bandage; but no medicine was given.

21. 5 A. M. Has had some sleep; the sickness, hiccough, and pain have subsided. There remains only a sense of soreness in the abdominal viscera; the skin is 2 Iittle dry.

R Syrup. papav. 3 i.

Liquor ammon, acet.

Mist. camph. aa 3 iii. $M$.

3 P. M. Has not had any evacuation by the bowels: gave three of the pills which were ordered yesterday, with three table spononfuls of the following mixture ;

Bk Magn. sulph. z zii.

Inf. sennæ $\zeta \mathrm{v}$.

Tinct. gentian. camp. $\xi$ i. fs $M$.

22. Has had two stools; rested well during the night, and appears quite well.

* This is the second case of this kind I have seen : the first occurred in May last, in a patient of the Finsbury Dispersary, aged 70, who did not appiy to the charity till a very late period of the disease. and died in 20 hours after the uperation. The diseased parts are preserved in my anatomical musequm. 
95. Has been sitting up, and walking about the room, for the last three days, without any inconvenience. The wound has not healed by the first intention, but the granulations look healihv.

Aug. 1. The wound has been dressed every second day, and is nearly healed; her health is quite good, and she does not feel any inconvenience.

Sept. 20. She has taken her accustomed exercise, and nursed a child without pain or inconvenience. Nor is there the least appearance of any protrusion of the hernia. The bandage has been continued to make pressure on the part, as some objections we started to wearing a truss.

JOHN TAUNTON.

LXV. An easy Method of forming all Kinds of Ovals, commonly known by the Name of Gardener's Quals*.

T The oval, as is well known, is an elliptical figure formed by a curved line, which re-enters into itself, and which is composed of several portions of a circle which have various centres.

The execution and demonstration of this figure pre-suppose a degree of knowledge which every body does not possess; but a method has long been known of forming it with exactitude in a practical manner; and an acquaintance with it will be sufficient for artists, gardeners, and other persons who wish to trace this figure: the following is a description of the method in question:

Every oval bas two diameters: one long like the line A B (Plate IX.), which is called the great diameter, and the other short, which is called the small diameter, like the line $\mathbf{F} \mathbf{H}$, which forms with A B four right angles, since it is perpendicular to it. These two lines are reciprocally interseated at their middle point, whatever length we may suppose these two diameters to have.

It is requisite to trace a curved line, which passes at the different points A FBH, where the great and small diameter terminate.

With this view, from the middle of the great diameter to the point $L$ trace the small arcs to the points $G$ and $D$, which ought to be equally distant from the point $L$, and consequently from the points $\mathrm{A}$ and $\mathrm{B}$.

Plant at the point of intersection of these two arcs, $C$ and

- Bil. Phys. Eron.2d Semestre 1811, p. 266. 